\title{
Evaluation of quarter-based selective dry cow therapy using Petrifilm on-farm milk culture: A randomized controlled trial
}

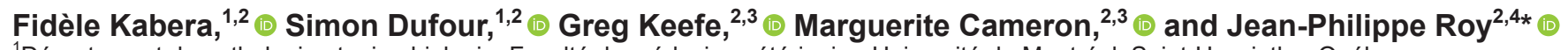 \\ ${ }^{1}$ Département de pathologie et microbiologie, Faculté de médecine vétérinaire, Université de Montréal, Saint-Hyacinthe, Québec, \\ Canada J2S 2M2 \\ ${ }^{2}$ Mastitis Network, Saint-Hyacinthe, Québec, Canada J2S 2M2 \\ ${ }^{3}$ Department of Health Management, Atlantic Veterinary College, University of Prince Edward Island, Charlottetown, Prince Edward Island, \\ Canada C1A 4P3 \\ ${ }^{4}$ Département de sciences cliniques, Faculté de médecine vétérinaire, Université de Montréal, Saint-Hyacinthe, Québec, Canada J2S 2M2
}

\section{ABSTRACT}

The objective of this randomized controlled trial was to assess the efficacy of an on-farm culture system using Petrifilm (3M, London, ON, Canada) for targeted treatment decisions at the quarter level at dry-off and its effects on dry period intramammary infections (IMI) and udder health and milk production in the subsequent lactation. A total of 568 cows (2,247 quarters) from 9 dairy herds with bulk tank somatic cell count $<250,000$ cells/mL in Québec, Canada, were systematically enrolled and randomly allocated to 4 groups: 2 quarter-based selective (QSDCT) groups, using results of quarter-milk culture on Petrifilm, and 2 blanket dry cow therapy (BDCT) groups. The 2 QSDCT groups consisted of (1) antimicrobial to infected quarters and internal teat sealant (ITS) to healthy quarters (QSDCT/ITS); and (2) antimicrobial and ITS to infected quarters and ITS to healthy quarters (QSDCT+ITS/ ITS). The 2 BDCT groups were (1) antimicrobial alone to all quarters (BDCT); and (2) antimicrobial and ITS to all quarters (BDCT+ITS). Quarter milk samples were collected at dry-off and after calving for routine bacteriological culture at the laboratory to monitor IMI; data on milk production, somatic cell count, and clinical mastitis recorded up to $120 \mathrm{~d}$ in milk were retrieved from health and DHI records. The probability of avoiding antimicrobial treatment in QSDCT groups was estimated at $48.3 \%$ (95\% confidence interval: 35.7, 60.9). There was no significant difference between the 4 treatment groups regarding acquisition of new IMI $(15.9,13.2,15.8$, and $15.1 \%$ probability for BDCT, BDCT+ITS, QSDCT/ITS, and QSDCT+ITS/ITS, respectively) or persistence of existing IMI $(3.2,2.1$, 3.4 , and $2.7 \%$ probability, respectively) over the dry period. In the subsequent lactation, there was no dif-

Received August 11, 2019.

Accepted April 1, 2020.

*Corresponding author: jean-philippe.roy@umontreal.ca ference between groups regarding incidence of clinical mastitis $(2.4,3.7,2.9$, and $1.7 \%$ respectively for BDCT, BDCT+ITS, QSDCT/ITS, and QSDCT+ITS/ITS), mean milk somatic cell score $(1.7,2.0,2.0$, and 2.0 respectively), or mean daily milk production $(43.8,44.2$, 43.2 , and $42.6 \mathrm{~kg} / \mathrm{d}$, respectively) during the first 120 $\mathrm{d}$ in milk. In conclusion, QSDCT using the Petrifilm on-farm culture system to detect infected quarters at dry-off is an interesting option to decrease antibiotic use without any negative effects on udder health or milk production in the first $120 \mathrm{~d}$ of the subsequent lactation compared with BDCT.

Key words: dry period, selective antibiotic treatment, on-farm culture, mastitis, intramammary infection

\section{INTRODUCTION}

Blanket dry cow therapy (BDCT), where all quarters of all cows are treated with an antimicrobial at dry-off, was introduced many years ago (Neave et al., 1969) and is widely used by dairy farmers. This practice is used to increase the elimination of existing IMI at dry-off and prevent the occurrence of new IMI during the dry period. However, with changes in mastitis epidemiology and increasing public health concerns regarding the overuse of antimicrobials, selective dry cow therapy (SDCT) is a potential alternative to BDCT to reduce antimicrobial usage in dairies (Rindsig et al., 1978, 1979). When using an SDCT approach, antimicrobial treatment is reserved for cows or quarters known to have or suspected of having an IMI, with uninfected cows and quarters not receiving antimicrobial treatment. In addition, internal teat sealants (ITS) have been shown to be a very effective nonantimicrobial alternative to prevent new IMI during the dry period (Woolford et al., 1998; Huxley et al., 2002; Sanford et al., 2006).

The success of an SDCT approach can be measured by the relative reduction in antimicrobial usage at dryoff, the absence of a negative effect on IMI incidence 
and elimination during the dry period, and udder health and production in the subsequent lactation. The economic impact of an SDCT approach is also an important factor, although, in some contexts, it may not be a primary concern. In fact, in some countries, prophylactic use of antimicrobials is prohibited. The success of an SDCT approach will be strongly influenced by the ability to determine correctly the infection status of the quarter or cow so that the appropriate treatment is applied at dry-off (Huxley et al., 2002; Robert et al., 2008; Torres et al., 2008). Since the introduction of SDCT, different methods of selecting cows with an IMI have been reported (Browning et al., 1990; Torres et al., 2008; Cameron et al., 2013), but previous lactation SCC alone or combined with the history of clinical mastitis (CM) is the most commonly used (Torres et al., 2008; Scherpenzeel et al., 2014). However, the accuracy of this diagnostic approach is not perfect, with sensitivity and specificity of approximately 70 and 64\%, respectively (Torres et al., 2008). Selective dry cow therapy based on on-farm culture diagnostic methods has been reported (Cameron et al., 2013, 2014, 2015), with sensitivity and specificity of 85.2 and $73.2 \%$, respectively, and without any negative effect on udder health during the subsequent lactation.

An SDCT protocol for low-SCC herds, using culture results from Petrifilm (commercially available dehydrated culture media; 3M Petrifilm, London, ON, Canada) to differentiate infected from healthy cows has been investigated (Cameron et al., 2013, 2014, 2015). This protocol resulted in a reduction of $22 \%$ in antimicrobial use at dry-off, with no negative effect on udder health or milk production in the next lactation. However, these authors reported that, based on bacteriological culture in the laboratory, $82.7 \%$ of quarters were healthy at dry-off and could have been left untreated with antimicrobials. Therefore, because many cows had only 1 or 2 infected quarters, we hypothesized that selection at the quarter level based on on-farm milk culture may further reduce antimicrobial use associated with the SDCT approach, without any harmful effect on udder health or milk production in the subsequent lactation. The objective of the current study was to determine the reduction in antimicrobial use and compare dry period IMI elimination and incidence rates and udder health and production in the first $120 \mathrm{~d}$ of the subsequent lactation between groups of cows treated using a BDCT protocol compared with a quarter-based SDCT protocol using Petrifilm.

\section{MATERIALS AND METHODS}

A randomized controlled trial was conducted to compare the effect of quarter-based SDCT to BDCT on
IMI incidence and elimination during the dry period, and on SCC, CM incidence, and mean daily milk production (in $\mathrm{kg} / \mathrm{d}$ ) during the first 120d of the subsequent lactation. The research protocol was approved by the Animal Ethics Committee of the Université de Montréal (15-Rech-1774). The reporting guidelines for randomized controlled trials for livestock and food safety were used to design the study and report the results (O'Connor et al., 2010; Sargeant et al., 2010).

\section{Participants}

A convenience sample of 9 dairy herds in Québec, Canada, was selected. Eligible herds were selected based on proximity to the Faculty of Veterinary Medicine of the Université de Montréal, Québec, Canada, with a maximum distance of $150 \mathrm{~km}$. These herds averaged 92 lactating cows (range of 50 to 200) and a 305-d mean milk production of $9,841 \mathrm{~kg}$ (range of 9,050 to $11,369 \mathrm{~kg}$ ). Herd inclusion criteria included (1) an average bulk tank $\mathrm{SCC}<250,000$ cells $/ \mathrm{mL}$ over the last 12 mo; (2) participation in a DHI program with regular milk testing; (3) willingness to commit to the project protocol; and (4) agreement to set dry-off day at 2 -wk intervals to allow the research team to collect milk samples and assist in setting up the on-farm culture on the day before dry-off. From these farms, all cows that entered the dry period between July 2015 and May 2016 were considered for inclusion in the trial. Enrolled cows had no CM or antimicrobial treatment during 14 d before dry-off, an expected dry period of 35 to 75 $\mathrm{d}$, and at least 3 functional quarters. Cows that failed to meet the inclusion criteria were not included in the randomized controlled trial and were treated according to routine farm procedures for dry-off.

\section{Treatment Allocation}

Before initiating the study, random numbers between 1 and 4 were generated by an investigator not involved with the enrollment of cows using a random number generator function (RANDBETWEEN function of the Excel 2013 software; Microsoft Corp., Redmond, WA). Sealed and numbered (1 through 600) envelopes were prepared, each containing a random number later used to assign each cow to 1 of the 4 treatment groups. At each farm visit, an animal health technician and the first author allocated enrolled cows into the 4 treatment groups. When more than one cow was to be dried off on a given day, cows were ordered as presented by the herd health software. Thus, the first envelope was assigned to the first cow on the list, the second envelope to the second cow on the list, and so on. Envelopes were opened only after confirmation of eligibility of the 
cow and before collecting milk samples. Farm staff were not involved in treatment allocation and therefore, they were unable to intentionally select a treatment group or keep a particular cow out of the study.

\section{Interventions}

The first and second groups of cows were positive control groups and were treated as follows: (1) intramammary infusion of antimicrobial alone $(200,000 \mathrm{IU}$ of Penicillin G Procaine and $400 \mathrm{mg}$ of Novobiocin; Novodry Plus, Zoetis Canada, Kirkland, QC, Canada) to all quarters of all cows (BDCT); and (2) intramammary infusion of the same antimicrobial and an ITS $(4 \mathrm{~g}$ of an ITS containing $65 \% \mathrm{wt} / \mathrm{wt}$ of bismuth subnitrate; Orbeseal, Zoetis Canada) to all quarters of all cows (BDCT+ITS). The third and fourth groups of cows were the quarter-based SDCT (QSDCT) groups. In these latter groups, healthy and infected quarters were first differentiated using Petrifilm Aerobic Count plates (3M Petrifilm) used in an on-farm culture system. Briefly, using an aseptic sampling technique (National Mastitis Council, 2017b), single quarter milk samples were collected and cultured using Petrifilm Aerobic Count plates on the day before dry-off. Both the milk sample collection and Petrifilm on-farm culture were performed by research team members. One milliliter of quarter milk was added to $9 \mathrm{~mL}$ of sterile water to make a 1:10 dilution. One milliliter of diluted milk was cultured on a Petrifilm Aerobic Count plate and incubated on-farm at $35^{\circ} \mathrm{C}$ for $24 \mathrm{~h}$ in a TurboFan Hova-Bator (GQF Manufacturing, Savannah, GA). Considering a dilution factor of 1:10, a single colony-forming unit was equivalent to $10 \mathrm{cfu} /$ $\mathrm{mL}$ of milk. Culture results on Petrifilm were read by the producer on the day of dry-off and quarters were classified as infected if $\geq 5$ colonies (McCarron et al., 2009) were present on the Petrifilm plate (equivalent to $\geq 50 \mathrm{cfu} / \mathrm{mL}$ of milk). Cows were considered healthy if $<5$ colonies could be visualized. In the third group (QSDCT/ITS), infected quarters were treated with an intramammary infusion of the previously described antimicrobial, and healthy quarters received only the described ITS. Thus, quarters of a given cow could be treated differently depending on infection status. In the last group (QSDCT+ITS/ITS), infected quarters received an intramammary infusion of the described antimicrobial and ITS, whereas healthy quarters received the ITS only, thus allowing for different treatment for the quarters of the same cow. Allocating cows to these 4 treatment groups allowed for a comparison of QSDCT and BDCT in herds not using ITS and where only an antimicrobial is used (QSDCT/ITS vs. BDCT) and for a comparison of QSDCT and BDCT in herds usually treating all quarters with antimicrobials and an ITS (QSDCT+ITS/ITS vs. BDCT+ITS).

All treatments were applied by farm personnel immediately after the last milking at dry-off, following the procedures recommended by the Canadian Bovine Mastitis and Milk Quality Research Network's factsheet on administration technique for intramammary treatment in dairy cows (CBMQRN, 2010). At the farm level, treatments were recorded to verify accordance with the study protocol. Producers had to complete one form per cow regarding the Petrifilm results and the treatment administered per quarter. Also, the research team had to verify after enrollment of each cow in the study that they were allocated to the correct group and that the interpretation of the Petrifilms by the producer was done correctly. To achieve this, Petrifilms were scanned using an automated 3M Petrifilm reader (3M Canada, London, ON, Canada), which provided an automatized colony count. Farm personnel were not blinded to treatment groups, as they were responsible for administering treatments at dry-off.

\section{Outcomes and Predictor}

Outcomes. Four outcomes of interest were investigated, with the quarter as the statistical unit: (1) probability of not receiving an antimicrobial for quarters of cows randomized to a QSDCT; (2) probability of development of a new IMI over the dry period (for all groups); (3) probability of persistence of an existing IMI over the dry period (for all groups); and (4) probability of experiencing $\geq 1$ case of CM during the first 120 DIM of the subsequent lactation (for all groups). Two outcomes of interest were investigated, with the cow as the statistical unit: (1) mean daily milk production (in $\mathrm{kg} / \mathrm{d}$ ) during the first 120 DIM of the subsequent lactation, and (2) mean SCS during the first 120 DIM of the subsequent lactation.

Predictor. The cow's assigned treatment group (BDCT vs. BDCT+ITS vs. QSDCT/ITS vs. QSDCT+ITS/ITS) was the only predictor of interest and was used to describe the effect of QSDCT on udder health and milk production parameters.

\section{Data Collection}

One farm discontinued DHI testing during the course of the project. Data on milk production were, therefore, extracted from the farm milking system software (for the herd that discontinued DHI testing during the study), and monthly DHI data were used for the other 8 herds. In our analyses, we used the daily mean milk production (in $\mathrm{kg}$ ) of the first $16 \mathrm{wk}$ in milk for the farm from which we could get weekly milk production 
data and the daily mean milk production (in $\mathrm{kg}$ ) of the first 4 DHI tests following calving for the other farms. Data on SCC during the first 120 DIM (4 milk tests) were extracted from monthly DHI data for all participating farms. Only cows with data from $\geq 2$ milk tests ( 8 herds) or 8 wk of data ( 1 herd) were included in the final analysis of the effect of treatment group on milk production and SCS. Somatic cell count measurement (in cell $/ \mathrm{mL}$ ) of each test was converted to SCS using equation [1] (Shook, 1993), and the arithmetic mean of the different SCS measurement was then computed:

$$
\mathrm{SCS}=\frac{\log _{\mathrm{e}}(\mathrm{SCC} / 100,000)}{0.6931}+3 .
$$

\section{Milk Samples for Bacteriological Analyses}

Using an aseptic sampling technique (National Mastitis Council, 2017b), for all enrolled cows, single quarter milk samples were collected on all quarters on (1) the day before dry-off ( $\mathbf{S} 1$; collected by research team); (2) d 3 to 4 after calving (S2; collected by farm personnel); (3) d 5 to 18 after calving (S3, collected by research team); and (4) for all CM cases occurring between calving and 120 DIM (S4, collected by farm personnel). Also, health records (DSAHR, animal health management software, Association des médecins vétérinaires praticiens du Québec, Saint Hyacinthe, Québec, Canada) were used to obtain information on $\mathrm{CM}$ cases that were not reported by farmers on the project documents. The S2 and S4 samples were kept frozen at $-20^{\circ} \mathrm{C}$ at the farm until the next farm visit (occurring every other week). Milk samples collected by the research team were placed on ice and transported to the laboratory at the Faculty of Veterinary Medicine of the Université de Montréal. They were frozen at $-20^{\circ} \mathrm{C}$ before monthly shipment to the Maritime Quality Milk research laboratory at the University of Prince Edward Island, where culture and bacterial identification were conducted. Laboratory personnel were blinded to treatment allocation when conducting bacteriological analyses.

\section{Laboratory Bacteriological Culture and Identification of Pathogens}

Milk Bacteriological Culture. Milk samples were thawed and cultured in the Maritime Quality Milk research laboratory using standardized methods outlined in the Laboratory Handbook on Bovine Mastitis (National Mastitis Council, 2017a). Briefly, disposable plastic loops were used to streak $0.01 \mathrm{~mL}$ of milk on bi-plates containing half Columbia agar $+5 \%$ sheep blood and half MacConkey agar. Plates were incubated at $35^{\circ} \mathrm{C}$ and examined for bacterial growth after 24 and $48 \mathrm{~h}$. Colonies were tentatively identified as staphylococci, streptococci, coliforms, or other pathogens based on colony growth characteristics, morphology, pattern of hemolysis, catalase reaction, and Gram stain. For each positive sample, the number of colony-forming units per $0.01 \mathrm{~mL}$ of milk was enumerated up to a maximum of 10 colonies. We attempted to identify all phenotypically distinct microorganisms recovered on a plate, regardless of the number of colonies. However, samples with $\geq 3$ phenotypically different colony types were classified as contaminated and, in that case, bacterial identification was not attempted. Nevertheless, if a contaminated sample had one or more hemolytic colonies (suspected to be Staphylococcus aureus), the hemolytic colonies were enumerated and analyzed further. If Staph. aureus was isolated in a contaminated sample, the quarter was considered infected (vs. contaminated). Yeast and Prototheca spp. were recorded based on Gram stain results. Colonies of bacteria were subcultured individually on blood agar plates to obtain pure cultures for further classification using matrixassisted laser desorption/ionization time-of-flight mass spectrometry (MALDI-TOF MS). The description of the MALDI-TOF MS methodology is presented in the Supplementary Material (https://doi.org/10.3168/jds .2019-17438).

Definition of IMI, New IMI, and Persistence of IMI Over the Dry Period. The presence of $\geq 1$ $\mathrm{cfu} / 0.01 \mathrm{~mL}$ of milk of any bacteria was considered sufficient to qualify a quarter as having an IMI (Dohoo et al., 2011). If an IMI by a specific pathogen species was present in the first postcalving sample (S2) and if that same pathogen species was not found in the drying-off sample (S1), then the quarter was considered to have experienced a new IMI during the dry period.

Because ITS are used mainly to prevent new IMI by environmental bacteria (IMIenv), we also investigated specifically new IMI by these types of pathogens (new IMIenv), by creating a second new IMI definition, which further excluded new IMI by contagious mastitis pathogens (mainly Corynebacterium bovis, Staphylococcus aureus, Streptococcus agalactiae, Mycoplasma bovis, or other Mycoplasma species). All enrolled quarters, irrespective of their dry-off IMI status, were considered at risk of acquiring a new IMI or new IMIenv.

In contrast with new infections, only infected quarters at dry-off were considered at risk of IMI persistence over the dry period. A persistent IMI over the dry period was considered if a specific pathogen species found at dry-off (S1) was found in the first postcalving 
sample (S2). If a quarter was infected with 2 pathogens at $\mathrm{S} 1$, the presence of any of the 2 pathogens in $\mathrm{S} 2$ was interpreted as a persistent IMI.

Finally, to investigate the effect of using a single postcalving sample (S2) to estimate new IMI, new IMIenv, and persisting IMI, these outcomes were all also investigated, but using case-definitions where both first (S2) and second (S3) postcalving samples were considered and using parallel interpretation of the 2 postcalving samples (i.e., $\geq 1$ positive test is interpreted as presence of an IMI).

Missing IMI Status. The information on new IMI or new IMIenv or IMI persistence was, therefore, missing, if (1) sample S1 was contaminated; or (2) if sample S2 was missing or contaminated. Moreover, the new IMI, new IMIenv, and IMI persistence statuses of a quarter over the dry period were considered undetermined if a bacteria could not be identified at the species level, such as Staphylococcus spp. or Corynebacterium spp., at either or both dry-off and postcalving time points.

\section{Statistical Analyses}

The primary unit of statistical analyses was the quarter. Descriptive statistics of the different outcomes and the main predictor were first explored; then, univariable analysis of the effect of treatment group was carried out for the different outcomes. First, to estimate the reduction in antimicrobial use resulting from the QSDCT, we computed the probability of being treated with antimicrobials in quarters allocated to the 2 QSDCT groups. To achieve this, we used a generalized linear mixed regression model with a logit link and using adaptive Gauss-Hermite quadrature for estimation in Stata/IC 11.0 (StataCorp, College Station, TX). Joe (2008) evaluated different estimation procedures (e.g., Gauss-Hermite, Laplace) for generalized mixed model and reported that Gauss-Hermite quadrature was the most accurate. In that model, the outcome was simply having received an antimicrobial or not at drying-off. The model contained only an intercept and no fixed predictors, and cow and herd random intercepts were included. Then, we estimated the effect of treatment allocation on the following dichotomous outcomes: (1) odds of new IMI or new IMIenv over the dry period; (2) odds of IMI persistence over the dry period; and (3) odds of having CM between calving and 120 DIM. Generalized linear mixed models (one for each of the 4 described outcomes) with a logit link and cow and herd random intercepts were used. In these models, the sole fixed predictor was treatment group. The odds of being treated with an antimicrobial, of new IMI/new IMIenv or IMI persistence or having CM between calving and
120 DIM were then converted into population-average estimates and further into a probability using the invert logit function using the Stata margin command.

A supplementary analysis was conducted to investigate the comparison of blanket treatment, in general (BDCT and BDCT+ITS combined) versus selective treatment in general (QSDCT/ITS and QSDCT+ITS/ ITS combined). Also, we investigated the effect of treatment group on mean SCS and mean daily milk production at 120 DIM. For these quantitative outcomes, generalized linear mixed models with cow and herd random intercepts were used, with treatment group as the sole fixed predictor. These models were estimated using the MIXED procedure of SAS (version 9.4, SAS Institute Inc., Cary, NC).

For all models, the significance threshold was set at 0.05. A priori adjustments for multiple comparisons were considered using the Bonferroni method (results are not presented, as no significant differences were found between groups). Only subjects with complete information on all variables in the final model were included in the analyses (i.e., complete case analysis). For continuous outcomes, homoscedasticity and normality of residuals were evaluated by examination of residual plots.

The results obtained by the automated 3M Petrifilm reader were used to evaluate the ability of producers to correctly identify infected quarters based on on-farm culture results. The level of agreement between the producer and the automated reader results was assessed using McNemar's test for paired data, followed by calculation of the kappa statistic.

\section{Sample Size Estimation}

Sample size calculations were conducted a priori using the POWER procedure of the SAS 9.4 software (SAS Institute Inc.). Assuming a risk of new IMI = 0.31 per quarter for a dry period $>45 \mathrm{~d}$ (Dufour and Dohoo, 2013), a type I error rate of 0.05 , and a power of $90 \%$ to detect an odds ratio of 1.5 , we estimated that a sample size of 140 cows (560 quarters) per treatment group was required. Stated differently, with this sample size, we would have $90 \%$ power to differentiate statistically a new IMI incidence of $0.31(174 / 560)$ from one of $0.40(226 / 560)$ IMI/quarter per dry period. Because follow-up losses, possible contamination of samples, and clustering of quarters in cow and cows in herds were ignored for those calculations, the true power was more likely to be less than $90 \%$ but still close to $80 \%$. The randomization and treatment were done at the cow level but the unit for statistical analyses was the quarter. 


\section{RESULTS}

\section{Cow Enrollment and Descriptive Statistics: Participants}

Nine dairy farms with primarily Holstein cows were selected in Québec, Canada. In total, 569 cows $(2,251$ quarters) were recruited at dry-off between July 2015 and May 2016 (mean = 63 cows/herd; range: 26-165 cows/herd) and were randomly allocated in the 4 treatment groups (average of 142 cows per group, range $=$ 133 to 153). Twenty-five quarters were not functional at drying-off and consequently did not receive any treatments. Figure 1 describes the recruitment and followup of cows and quarters throughout the randomized controlled trial. The number of quarters as a function of group allocation, treatment administered at dry-off, and IMI status at dry-off, with descriptive statistics on daily milk production (in $\mathrm{kg} / \mathrm{d}$ ) and SCS of last DHI test before dry-off and during the first 120 DIM of the subsequent lactation are described in Table 1. Briefly, the 4 treatment groups did not differ at enrollment regarding IMI prevalence at dry-off $(P=0.44)$, last DHI test SCS $(P=0.63)$, or last DHI test daily milk production $(P=0.28)$. On the pre-dry sample, $330 / 575$ and $316 / 539$ quarters were negative on Petrifilm in the QSDCT/ITS and QSDCT+ITS/ITS groups, respectively, and therefore only received an ITS at drying-off. Thus, $646 / 1,114(58 \%)$ of QSDCT quarters were not treated with antimicrobials. Prediction from the generalized linear mixed model indicated that 48.3\% (95\% CI: 35.7, 60.9 ) of quarters would be left untreated when using QSDCT. Almost perfect agreement between Petrifilm results obtained by the producer and those obtained by the automated Petrifilm reader was observed, with a kappa value of 0.89 (95\% CI: 0.86, 0.92).

A total of 119 quarters had a CM between calving and 120 DIM, but farm personnel only collected milk samples before antimicrobial treatment for 66 of these. Out of the 66 samples collected, $37(56.1 \%)$ yielded no growth. Pathogens retrieved from CM cases are presented in Supplemental Table S1 (https://doi.org/10

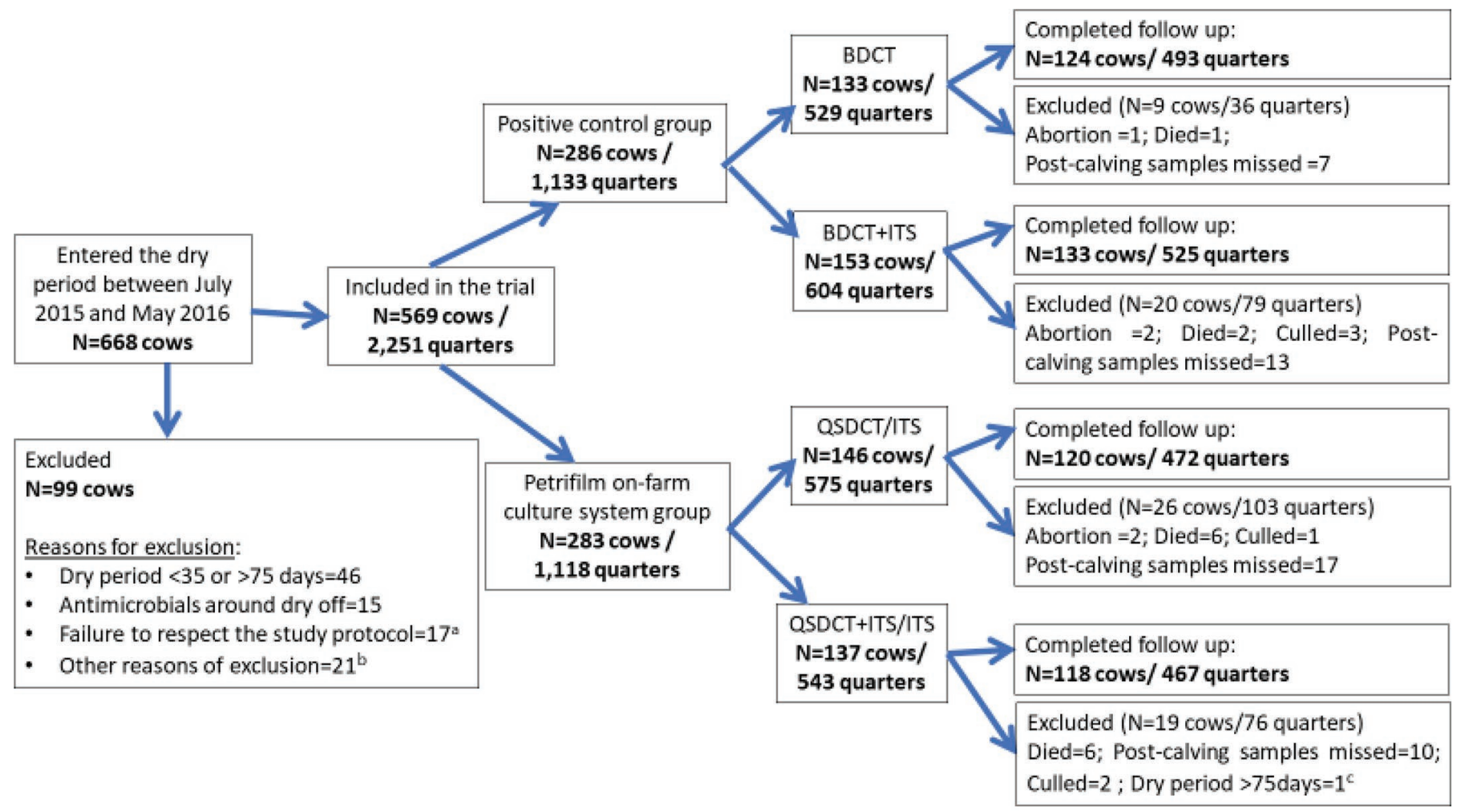

Figure 1. Illustration of the enrollment and follow-up of cows in a randomized controlled trial comparing 4 groups: (1) blanket dry cow therapy (BDCT); (2) BDCT and internal teat sealant (BDCT+ITS); (3) quarter-based selective dry cow therapy with antimicrobial for infected quarters and an ITS for healthy quarters (QSDCT/ITS); (4) QSDCT with antimicrobial and ITS for infected quarters and an ITS for healthy quarters (QSDCT+ITS/ITS). ' Failure to respect the protocol included cows not treated according to the treatment group (e.g., a cow recruited in group 1 and treated as per group 2), cows that received dry cow treatment twice, or cows in which there was a delay between sampling date and dry-off (e.g., cows dried off a week after the sampling date). ${ }^{\mathrm{b}}$ Other reasons included breed other than Holstein, difficult to handle, contamination of pre-dry Petrifilm (3M, London, ON, Canada) culture. ${ }^{\mathrm{c}}$ One cow was excluded a posteriori because the true length of the dry period was longer than the maximal acceptable value by a difference of more than $10 \mathrm{~d}$. 
.3168/jds.2019-17438). Briefly, among the 29 quarters for which bacteria were isolated, the most frequent pathogens were Staphylococcus aureus $(\mathrm{n}=6 / 30$ isolates), followed by Escherichia coli $(\mathrm{n}=3 / 30)$, Staphylococcus haemolyticus $(\mathrm{n}=3 / 30)$, and Streptococcus dysgalactiae $(\mathrm{n}=3 / 30)$.

Data on milk production following calving were missing for 66 cows (35 from a farm that discontinued DHI testing during the course of the study). Thus, the final analysis of the effect of treatment on milk production during the subsequent 120 DIM included 502 cows. One farm discontinued regular milk control during the project; thus, we failed to obtain SCC data for all cows. Data on SCS during the first 120 DIM were missing for 170 cows (including 138 cows from the farm that discontinued DHI testing during the course of the study). Thus, the final analysis of SCS included data from 398 cows.

\section{Outcomes and Estimations}

New IMI, Persistence of IMI, and CM in First 120 DIM of Next Lactation. Results from the multilevel logistic regression models indicated that treatment group was not significantly associated with new IMI $(P=0.74)$, new IMIenv $(P=0.78)$, IMI persistence over the dry period $(P=0.86)$, or occurrence of $\mathrm{CM}$ during the first $120 \mathrm{~d}$ of the next lactation $(P$ $=0.18)$. Model-estimated new IMI and new IMIenv cumulative incidences, IMI persistence prevalence, and CM cumulative incidence are reported in Table 2. Pathogens retrieved at dry-off and from dry period new IMI or persistent IMI for different treatment groups are presented in Supplemental Table S2 (https://doi.org/ 10.3168/jds.2019-17438).

When collapsing all cows into 2 treatment groups (blanket vs. selective), again we did not observe significant differences for new IMI $(P=0.63)$, new IMIenv $(P$ $=0.64)$, IMI persistence over the dry period $(P=0.72)$, or occurrence of CM during the first $120 \mathrm{~d}$ of the next lactation $(P=0.25)$. Finally, conclusions of the study regarding IMI results were not affected whether only the first (S2) or both (S2 and S3) postcalving samples were considered in the case definition.

Mean Daily Milk Production in the Subsequent 120 DIM. The distribution of mean daily 120 DIM milk production per treatment group is illustrated in Table 1. We did not observe a significant effect of the treatment group on milk production during 120 DIM after calving $(P=0.35)$. Similarly, no significant effect $(P=0.20)$ was observed when we compared the group of cows selectively treated and those that received blanket dry cow therapy (selective vs. blanket).

Somatic Cell Score. The distribution of mean 120 DIM SCS per treatment group is illustrated in Table 1. No significant effect of treatment was observed on SCS during 120 DIM after calving when considering each treatment group individually $(P=0.74)$ or cows

Table 1. Distribution of quarters and their characteristics as function of group allocation

\begin{tabular}{|c|c|c|c|c|}
\hline \multirow[b]{2}{*}{ Item } & \multicolumn{4}{|c|}{ Treatment group $^{1}$} \\
\hline & $\mathrm{BDCT}$ & BDCT+ITS & QSDCT/ITS & QSDCT+ITS/ITS \\
\hline Antimicrobial & 529 & 0 & 245 & 0 \\
\hline Antimicrobial and internal teat sealant & 0 & 604 & 0 & 223 \\
\hline Internal teat sealant alone & 0 & 0 & 330 & 316 \\
\hline Quarters receiving an antimicrobial $^{2}(\%)$ & 100 & 100 & 42.6 & 41.4 \\
\hline Daily mean milk production (in $\mathrm{kg} / \mathrm{d}$ ) & $23.7^{\mathrm{a}}$ & $24.1^{\mathrm{a}}$ & $25.5^{\mathrm{a}}$ & $23.2^{\mathrm{a}}$ \\
\hline $\mathrm{SCS}$ & $2.7^{\mathrm{a}}$ & $2.8^{\mathrm{a}}$ & $2.5^{\mathrm{a}}$ & $2.7^{\mathrm{a}}$ \\
\hline \multicolumn{5}{|l|}{ Subsequent lactation 0-120 DIM } \\
\hline \multicolumn{5}{|l|}{ Daily milk production (in kg/d) } \\
\hline Mean & $43.8^{\mathrm{a}}$ & $44.2^{\mathrm{a}}$ & $43.2^{\mathrm{a}}$ & $42.6^{\mathrm{a}}$ \\
\hline Interquartile range & $39.4-47.9$ & $39.5-47.8$ & $37.8-47.7$ & $37.6-46.7$ \\
\hline \multicolumn{5}{|l|}{ SCS } \\
\hline
\end{tabular}

${ }^{a}$ Values with the same letters within a row are not significantly different $(P>0.05)$.

${ }^{1} \mathrm{BDCT}=$ blanket dry cow therapy; BDCT $+\mathrm{ITS}=$ blanket dry cow therapy and internal teat sealant; QSDCT/ITS = quarter-based selective dry cow therapy with antimicrobial for infected quarters and an internal teat sealant for healthy quarters; QSDCT + ITS $/$ ITS $=$ quarter-based selective dry cow therapy with antimicrobial and internal teat sealant for infected quarters and an internal teat sealant for healthy quarters.

${ }^{2}$ Treatment decision was based on milk culture on Petrifilm aerobic count plates (3M Petrifilm, London, ON, Canada) for QSDCT/ITS and QSDCT+ITS/ITS groups.

${ }^{3}$ Intramammary infections were defined using laboratory-based milk culture followed with MALDI-TOF identification. 
Kabera et al.: QUARTER-BASED SELECTIVE DRY COW THERAPY

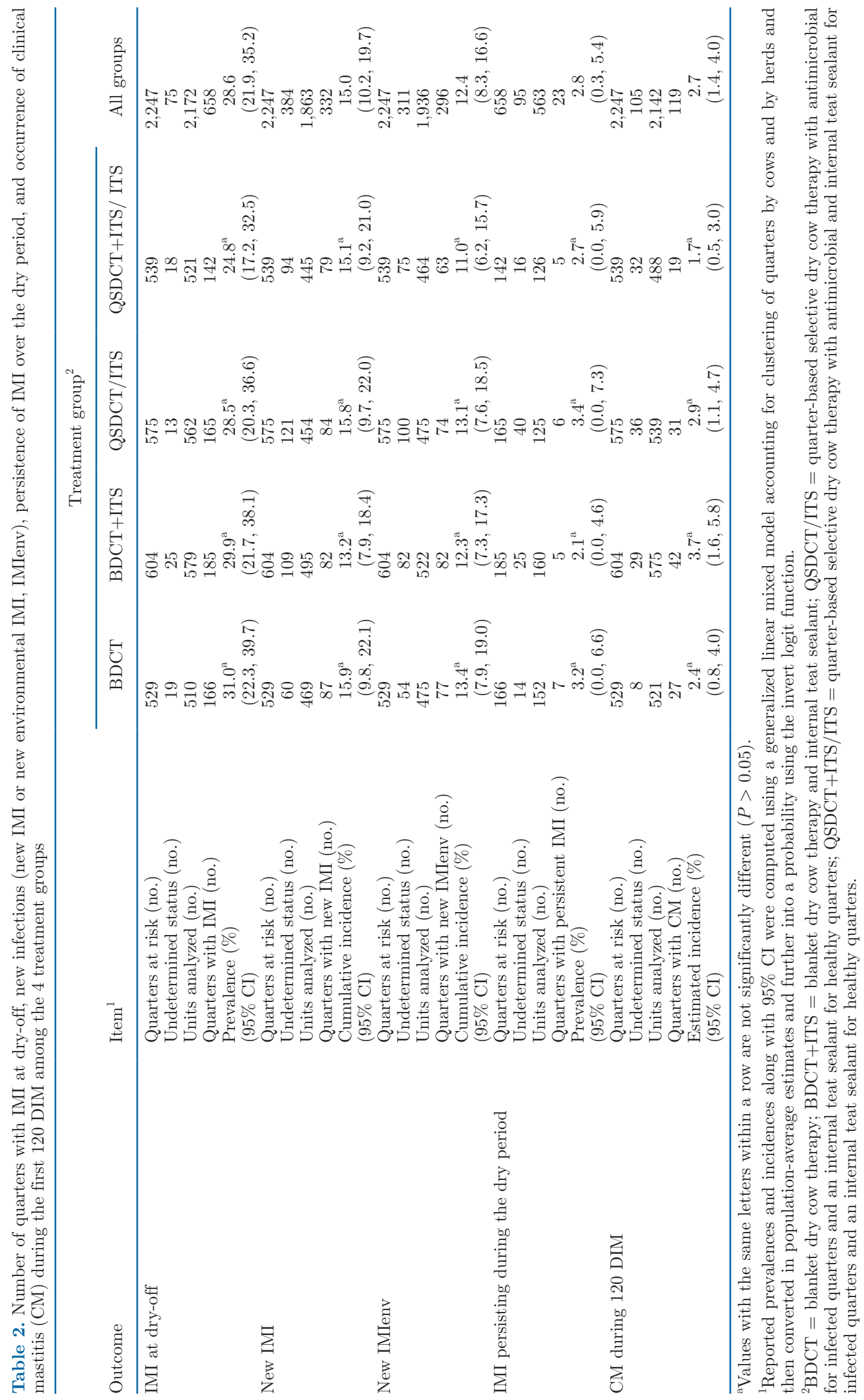


selectively treated versus blanket dry cow therapy $(P$ $=0.57$ ).

\section{DISCUSSION}

\section{Reduction in Antimicrobial Treatment}

The current study showed that it is possible to achieve substantial reductions in the use of antimicrobials, with comparable udder health and milk production indicators, when using a QSDCT approach with an ITS to protect untreated quarters compared with a BDCT approach. The application of the Petrifilm on-farm culture system at the quarter level resulted in a greater observed reduction of unnecessary antimicrobial use (58\%) compared with the reduction of $22 \%$ that was achieved when applied at the cow level (Cameron et al., 2014). With a QSDCT, if only 1 or 2 quarters are infected, only those are treated. However, previous studies reported on the interdependence of quarters within a cow for the acquisition of new IMI during the dry period, supporting the application of antimicrobials to all quarters of a cow (Browning et al., 1990; Berry et al., 2003; Robert et al., 2006). However, in these earlier studies, an ITS was not used to protect uninfected quarters. In fact, other studies reported that, regarding the acquisition of new IMI during dry-off, interdependence of quarters within a cow may be reduced when efficient prevention methods are applied to reduce the risk of new IMI (Berry et al., 2003; Robert et al., 2006).

A substantial reduction in the use of antimicrobials (50\%) has been reported by Scherpenzeel et al. (2014) with an SDCT program in low-SCC cows. However, they reported a higher incidence of new IMI during the dry period and CM during the first days (up to 100 DIM) of the next lactation.

In the current study, producers were able to accurately read the Petrifilm, given that the level of agreement between them and the automated reader of Petrifilm results was almost perfect (Landis and Koch, 1977). The interpretation of the Petrifilm Aerobic Count plate is facilitated by the presence of a bright pink color indicative of the presence of colonies.

\section{Prevalence of IMI at Dry-Off}

The prevalence of IMI at dry-off reported in this study was similar to that reported by Godden et al. (2003) and Torres et al. (2008), but greater than the prevalence reported in other studies (Pantoja et al., 2009; Arruda et al., 2013; Cameron et al., 2014). Differences may be explained by differences in the definition of IMI or methodology among studies (e.g., selection criteria of herds or cows) or management within herds.
For instance, a prevalence of $12.8 \%$ was reported by Pantoja et al. (2009) when IMI was defined as the presence of $\geq 3$ colonies in $0.01 \mathrm{~mL}$ of milk for any given pathogen.

The study by Cameron et al. (2014) considered, in addition to low bulk tank SCC herds, low SCC at the cow level (SCC $<200,000$ cells $/ \mathrm{mL}$ on the last 3 milk tests before drying off). Concerning SCC, we did not set a criterion when selecting cows to include in the current study. Thus, the potential inclusion of highSCC cows in this study may explain this difference in the prevalence of infections at dry-off compared with that reported by Cameron et al. (2014). In fact, a proportion of $37 \%$ of high-SCC cows (i.e., cows with a monthly SCC >200,000 cells $/ \mathrm{mL}$ for 3 last milk tests before dry-off) was reported by Cameron et al. (2014) for herds with a bulk tank SCC $\leq 250,000$ cells $/ \mathrm{mL}$.

\section{Effect of QSDCT Using Petrifilm On-Farm Culture}

The current study found no effect of treatment on risk for the development of new IMI or new IMIenv during the dry period or the persistence of IMI over the dry period or CM in early lactation up to 120 DIM or on SCC and mean milk production during the subsequent lactation up to 120 DIM. Our results are in accordance with Cameron et al. (2014) and Cameron et al. (2015), who reported comparable results of SDCT and BDCT when selection was made at the cow level. Similarly, Vasquez et al. (2018) and Rajala-Schultz et al. (2011) could not highlight any significant negative effect on udder health between BDCT and SDCT when using culture-independent selection criteria (DHI SCC data, CM history) to identify cows to be treated in the SDCT group.

In contrast to the current study, other studies on SDCT reported a higher risk of new IMI incidence or CM or an elevated SCC in selectively dry-treated cows compared with groups of cows receiving BDCT (Rindsig et al., 1978; Berry and Hillerton, 2002; Scherpenzeel et al., 2014). However, in those earlier studies, cows not receiving antimicrobials were left untreated and without an ITS. Consequently, they were not protected from new IMI during the dry period. The efficacy of ITS in the prevention of new IMI over the dry period has been reported previously (Woolford et al., 1998; Huxley et al., 2002; Dufour et al., 2019). Regarding SCC in early lactation, other studies reported no difference between ITS and antimicrobial treatment when they were used in cows with a low SCC before drying off (Sanford et al., 2006; Green et al., 2008).

Previous studies (Woolford et al., 1998; Huxley et al., 2002; Cook et al., 2005) reported that the additional protective effect of ITS, when used in conjunction with 
an antimicrobial, was not demonstrated in low-SCC cows. However, this combination has been recommended in high-SCC herds where cows are at high risk of new IMI during the dry period (Cook et al., 2005). A significant effect was also reported by Godden et al. (2003) and Mütze et al. (2012). In contrast, the current study did not show a significant difference between the use of an antimicrobial alone and its combination with an ITS at dry-off. This difference may be explained by the level of SCC of selected cows or herds, or by the length of the dry period. We may expect to detect a greater benefit of a combination of antimicrobial and ITS with longer dry periods. In fact, Berry and Hillerton (2007) reported a significantly lower incidence of new IMI during the dry period for cows receiving the combination treatment compared with antimicrobial alone, but the difference was not significant when the dry period was $<10 \mathrm{wk}$.

\section{Post Hoc Power Estimation}

Post hoc power calculations were conducted using the observed risk of new IMI (0.15 new IMI/quarter), and the approximate number of available observations (around 450 observations per group). With these numbers, the current study had $90 \%$ power to detect an odds ratio $\geq 1.7$ (or $\leq 0.59$ ). Stated differently, with this sample size, we had $90 \%$ power to differentiate statistically a new IMI incidence of $0.15(69 / 450)$ from one of $0.23(104 / 450) \mathrm{IMI} /$ quarter.

\section{Limitations of the Study}

One farm discontinued DHI testing over the course of the project and as a result, we were unable to obtain SCC data for the remaining study period. However, when statistical analyses for the effect of treatment group on SCC were performed both with and without the herd with missing data, the results and conclusions did not change substantially. After excluding that herd, we observed mean SCS of 1.7, 2.0, 1.9, and 1.9 for the BDCT, BDCT+ITS, QSDCT/ITS, and QSDCT+ITS/ ITS groups, respectively. For the effect of treatment group on milk production during the first $120 \mathrm{~d}$ of the subsequent lactation, a mean daily production over 17 wk (1 farm without monthly DHI testing) and a mean of 4 monthly test days ( 8 farms) were used in our analyses. We assumed that $17 \mathrm{wk}$ is roughly equivalent to the 4 monthly test days. Moreover, because cows were randomly assigned to the 4 groups within each herd, the slight measurement difference between 17-wk measures and 4-mo measures should be balanced across groups.
In the current study, we were able to follow most of the typical guidelines recommended for randomized control trials. However, producers could not be blinded to treatment group assignment. The fact that producers were not blinded to treatment groups possibly affected follow-up of quarters or cows. For instance, it is possible that producers did follow more closely quarters or cows that did not receive an antimicrobial at dry-off, especially if they were expecting a detrimental health event in these animals. To ensure equal reporting in all 4 groups, at every visit on the farms, the research team asked dairy producers to make sure that all $\mathrm{CM}$ events were recorded. The other outcomes measured in this study were all objectives outcomes and, thus, the values reported would not be affected by the absence of blinding. Nevertheless, it is also possible that our dairy producers altered the level of care of their cows according to treatment group.

In our study, an IMI was defined by the presence of $\geq 1 \mathrm{cfu} / 0.01 \mathrm{~mL}$ of milk of any bacteria, as our objective was to identify as many infections as possible (Dohoo et al., 2011). This IMI definition was suggested to have high sensitivity and almost perfect specificity for most pathogens (Dohoo et al., 2011). Using $\geq 1 \mathrm{cfu} / 0.01 \mathrm{~mL}$ as a case definition, however, would result in a lower specificity than a $\geq 2 \mathrm{cfu} / 0.01 \mathrm{~mL}$ definition for some pathogens, such as the non-aureus staphylococci, but would yield substantially higher sensitivity (Dohoo et al., 2011). Nevertheless, for these latter pathogens, Haine et al. (2018) highlighted that, in a cohort study using the $\geq 1 \mathrm{cfu} / 0.01 \mathrm{~mL}$ case definition, the resulting bias would be toward the null value, and that using IMI definitions that are less sensitive and more specific (such as the $\geq 2 \mathrm{cfu} / 0.01 \mathrm{~mL}$ definition) would do very little to mitigate this bias when measuring association with an exposure (such as in the current study). Note that Streptococcus agalactiae and Mycoplasma species were not recovered in the current study. Because samples were frozen for, on average, 1 mo before culture, and because of the culture techniques used, we were not able to isolate Mycoplasma species. On the other hand, Streptococcus agalactiae, Mycoplasma bovis, and other Mycoplasma species are relatively uncommon in Canada (Olde Riekerink et al., 2006; Francoz et al., 2012; Bauman et al., 2018). Freezing may also have affected recovery of other pathogens, such as E. coli (Schukken et al., 1989). Another limitation of the current study was the absence of molecular characterization of our bacterial isolates to ensure that isolates recovered at dry-off and calving were similar, when estimating persistence of IMI across the dry period.

At the end of the project, several producers were interested in continuing to apply the selective dry cow 
treatment by themselves. However, long-term followup to monitor implementation was not performed. Nevertheless, 5 herds were clients of the bovine ambulatory clinic of the Faculty of Veterinary Medicine of the Université de Montréal and were therefore visited regularly after the end of the study. Of these 5, 4 continued selective dry cow therapy after the end of the project. However, 3 yr later, only 1 producer is still doing it. Two producers stopped after $1 \mathrm{yr}$ due to lack of time (increase herd size, built new facilities, not enough staff) and one producer stopped after $2 \mathrm{yr}$ because the employee in charge of this procedure left the business. Selective dry cow therapy requires more time and a certain expertise to identify cows or quarters to be treated compared with blanket dry cow therapy. Moreover, performing milk culture may be a challenge for some dairy producers. Therefore, selective dry cow therapy based on milk culture is easier to implement in herds with a good level of management and motivated personnel.

\section{CONCLUSIONS}

A very substantial reduction in antimicrobial use was achieved using a QSDCT program relying on Petrifilm milk culture results, without any negative effects on udder health or milk production during the subsequent lactation. Compared with BDCT, a reduction in antimicrobial use of $58 \%$ was achieved.

\section{ACKNOWLEDGMENTS}

This research was supported by Agriculture and Agri-Food Canada (Ottawa, Ontario, Canada), and by additional contributions from Dairy Farmers of Canada (Ottawa, Ontario, Canada), the Canadian Dairy Network (Guelph, Ontario, Canada), and the Canadian Dairy Commission (Ottawa, Ontario, Canada) under the Agri-Science Clusters Initiative, through the Canadian Bovine Mastitis and Milk Quality Research Network (Saint Hyacinthe, Québec, Canada) research program, by Zoetis (Kirkland, Quebec, Canada), and by one of the authors (Dufour) NSERC-Discovery grant funds (RGPIN/435637-2013, Saint Hyacinthe, Québec, Canada). The first author was also supported by the NSERC-CREATE in Milk Quality program and the Fonds de recherche du Québec-Nature et technologies (FRQNT). As per the research agreement, aside from providing financial support, the funders have no role in the design and conduct of the studies, data collection and analysis, or interpretation of the data. Researchers maintain independence in conducting their studies, own their data, and report the outcomes regardless of the results. The decision to publish the findings rests solely with the researchers. We are grateful to all participating producers for their cooperation, Roxanne Mandeville (Faculté de médecine vétérinaire, Université de Montréal, Saint Hyacinthe, Canada) for her support as an animal health technician and Natasha Robinson (Atlantic Veterinary College, University of Prince Edward Island, Charlottetown, Canada) for the laboratory work. The authors have not stated any conflicts of interest.

\section{REFERENCES}

Arruda, A. G., S. Godden, P. Rapnicki, P. Gorden, L. Timms, S. S. Aly, T. W. Lehenbauer, and J. Champagne. 2013. Randomized noninferiority clinical trial evaluating 3 commercial dry cow mastitis preparations: I. Quarter-level outcomes. J. Dairy Sci. 96:44194435. https://doi.org/10.3168/jds.2012-6461.

Bauman, C. A., H. W. Barkema, J. Dubuc, G. P. Keefe, and D. F. Kelton. 2018. Canadian National Dairy Study: Herd-level milk quality. J. Dairy Sci. 101:2679-2691. https://doi.org/10.3168/jds .2017-13336.

Berry, E. A., and J. E. Hillerton. 2002. The effect of selective dry cow treatment on new intramammary infections. J. Dairy Sci. 85:112121. https://doi.org/10.3168/jds.S0022-0302(02)74059-9.

Berry, E. A., and J. E. Hillerton. 2007. Effect of an intramammary teat seal and dry cow antibiotic in relation to dry period length on postpartum mastitis. J. Dairy Sci. 90:760-765. https://doi.org/10 .3168/jds.S0022-0302(07)71560-6.

Berry, E. A., W. T. Johnston, and J. E. Hillerton. 2003. Prophylactic effects of two selective dry cow strategies accounting for interdependence of quarter. J. Dairy Sci. 86:3912-3919. https://doi.org/ 10.3168/jds.S0022-0302(03)73999-X.

Browning, J. W., G. A. Mein, M. Barton, T. J. Nicholls, and P. Brightling. 1990. Effects of antibiotic therapy at drying off on mastitis in the dry period and early lactation. Aust. Vet. J. 67:440-442. https: //doi.org/10.1111/j.1751-0813.1990.tb03055.x.

Cameron, M., G. P. Keefe, J. P. Roy, I. R. Dohoo, K. A. MacDonald, and S. L. McKenna. 2013. Evaluation of a 3M Petrifilm on-farm culture system for the detection of intramammary infection at the end of lactation. Prev. Vet. Med. 111:1-9. https://doi.org/10 .1016/j.prevetmed.2013.03.006.

Cameron, M., G. P. Keefe, J. P. Roy, H. Stryhn, I. R. Dohoo, and S. L. McKenna. 2015. Evaluation of selective dry cow treatment following on-farm culture: Milk yield and somatic cell count in the subsequent lactation. J. Dairy Sci. 98:2427-2436. https://doi.org/ $10.3168 / j d s .2014-8876$.

Cameron, M., S. L. McKenna, K. A. MacDonald, I. R. Dohoo, J. P. Roy, and G. P. Keefe. 2014. Evaluation of selective dry cow treatment following on-farm culture: Risk of postcalving intramammary infection and clinical mastitis in the subsequent lactation. J. Dairy Sci. 97:270-284. https://doi.org/10.3168/jds.2013-7060.

CBMQRN. 2010. Administration technique of intramammary treatment in dairy cows. Canadian Bovine Mastitis and Milk Quality Research Network. Accessed May 25, 2020. http://www .reseaumammite.org/tactic/wp-content/uploads/2020/02/EN _administration_treatment.pdf.

Cook, N. B., D. A. Pionek, and P. Sharp. 2005. An assessment of the benefits of Orbeseal $(R)$ when used in combination with dry cow antibiotic therapy in three commercial dairy herds. Bov. Pract. 39:83-94.

Dohoo, I. R., J. Smith, S. Andersen, D. F. Kelton, and S. Godden. 2011. Diagnosing intramammary infections: Evaluation of definitions based on a single milk sample. J. Dairy Sci. 94:250-261. https://doi.org/10.3168/jds.2010-3559.

Dufour, S., and I. R. Dohoo. 2013. Short communication: Relationship between herd intramammary infection incidence and elimination rate during the dry period. J. Dairy Sci. 96:1672-1676. https://doi .org/10.3168/jds.2012-5899. 
Dufour, S., V. Wellemans, J. P. Roy, P. Lacasse, A. Ordonez-Iturriaga, and D. Francoz. 2019. Non-antimicrobial approaches at drying-off for treating and preventing intramammary infections in dairy cows. Part 1. Meta-analyses of efficacy of using an internal teat sealant without a concomitant antimicrobial treatment. Anim. Health Res. Rev. 20:86-97. https://doi.org/10.1017/S1466252319000070.

Francoz, D., L. Bergeron, M. Nadeau, and G. Beauchamp. 2012. Prevalence of contagious mastitis pathogens in bulk tank milk in Quebec. Can. Vet. J. 53:1071-1078.

Godden, S., P. Rapnicki, S. Stewart, J. Fetrow, A. Johnson, R. Bey, and R. Farnsworth. 2003. Effectiveness of an internal teat seal in the prevention of new intramammary infections during the dry and early-lactation periods in dairy cows when used with a dry cow intramammary antibiotic. J. Dairy Sci. 86:3899-3911. https://doi .org/10.3168/jds.S0022-0302(03)73998-8.

Green, M. J., A. J. Bradley, G. F. Medley, and W. J. Browne. 2008. Cow, farm, and herd management factors in the dry period associated with raised somatic cell counts in early lactation. J. Dairy Sci. 91:1403-1415. https://doi.org/10.3168/jds.2007-0621.

Haine, D., I. Dohoo, D. Scholl, and S. Dufour. 2018. Diagnosing intramammary infection: Controlling misclassification bias in longitudinal udder health studies. Prev. Vet. Med. 150:162-167. https://doi .org/10.1016/j.prevetmed.2017.11.010.

Huxley, J. N., M. J. Green, L. E. Green, and A. J. Bradley. 2002. Evaluation of the efficacy of an internal teat sealer during the dry period. J. Dairy Sci. 85:551-561. https://doi.org/10.3168/jds S0022-0302(02)74108-8.

Joe, H. 2008. Accuracy of Laplace approximation for discrete response mixed models. Comput. Stat. Data Anal. 52:5066-5074. https:// doi.org/10.1016/j.csda.2008.05.002.

Landis, J. R., and G. G. Koch. 1977. The measurement of observer agreement for categorical data. Biometrics 33:159-174. https://doi . org $/ 10.2307 / 2529310$.

McCarron, J. L., G. P. Keefe, S. L. McKenna, I. R. Dohoo, and D. E. Poole. 2009. Laboratory evaluation of 3M Petrifilms and University of Minnesota Bi-plates as potential on-farm tests for clinical mastitis. J. Dairy Sci. 92:2297-2305. https://doi.org/10.3168/jds $.2008-1661$.

Mütze, K., W. Wolter, K. Failing, B. Kloppert, H. Bernhardt, and M. Zschöck. 2012. The effect of dry cow antibiotic with and without an internal teat sealant on udder health during the first $100 \mathrm{~d}$ of lactation: a field study with matched pairs. J. Dairy Res. 79:477484. https://doi.org/10.1017/S0022029912000477.

National Mastitis Council. 2017a. Laboratory Handbook on Bovine Mastitis. National Mastitis Council Inc., New Prague, MN.

National Mastitis Council. 2017b. Chapter 1: Sample collection and handling. Laboratory Handbook on Bovine Mastitis. 3rd ed. National Mastitis Council Inc., New Prague, MN.

Neave, F. K., F. H. Dodd, R. G. Kingwill, and D. R. Westgarth. 1969. Control of Mastitis in the Dairy Herd by Hygiene and Management. J. Dairy Sci. 52:696-707. https://doi.org/10.3168/jds.S0022 -0302(69)86632-4.

O'Connor, A. M., J. M. Sargeant, I. A. Gardner, J. S. Dickson, M. E. Torrence, C. E. Dewey, I. R. Dohoo, R. B. Evans, J. T. Gray, M. Greiner, G. Keefe, S. L. Lefebvre, P. S. Morley, A. Ramirez, W. Sischo, D. R. Smith, K. Snedeker, J. Sofos, M. P. Ward, and R. Wills. 2010. The REFLECT statement: Methods and processes of creating reporting guidelines for randomized controlled trials for livestock and food safety. J. Vet. Intern. Med. 24:57-64. https:// doi.org/10.1111/j.1939-1676.2009.0441.x.

Olde Riekerink, R. G., H. W. Barkema, S. Veenstra, D. E. Poole, R. T. Dingwell, and G. P. Keefe. 2006. Prevalence of contagious mastitis pathogens in bulk tank milk in Prince Edward Island. Can. Vet. J. 47:567-572.

Pantoja, J. C. F., C. Hulland, and P. L. Ruegg. 2009. Dynamics of somatic cell counts and intramammary infections across the dry period. Prev. Vet. Med. 90:43-54. https://doi.org/10.1016/j prevetmed.2009.03.012.
Rajala-Schultz, P. J., A. H. Torres, and F. J. DeGraves. 2011. Milk yield and somatic cell count during the following lactation after selective treatment of cows at dry-off. J. Dairy Res. 78:489-499. https://doi.org/10.1017/S0022029911000690.

Rindsig, R. B., R. G. Rodewald, A. R. Smith, and S. L. Spahr. 1978. Complete versus selective dry cow therapy for mastitis control. J. Dairy Sci. 61:1483-1497. https://doi.org/10.3168/jds.S0022 $-0302(78) 83753-9$.

Rindsig, R. B., R. G. Rodewald, A. R. Smith, N. K. Thomsen, and S. L. Spahr. 1979. Mastitis history, California Mastitis Test, and somatic cell counts for identifying cows for treatment in a selective dry cow therapy program. J. Dairy Sci. 62:1335-1339. https://doi .org/10.3168/jds.S0022-0302(79)83421-9.

Robert, A., N. Bareille, P. Roussel, B. Poutrel, V. Heuchel, and H. Seegers. 2006. Interdependence of udder quarters for new intramammary infection during the dry period in cows submitted to selective antibiotic therapy. J. Dairy Res. 73:345-352. https://doi .org/10.1017/S0022029906001981.

Robert, A., P. Roussel, N. Bareille, D. Ribaud, F. Serieys, V. Heuchel, and H. Seegers. 2008. Risk factors for new intramammary infections during the dry period in untreated dairy cows from herds using selective dry cow therapy. Animal 2:247-254.

Sanford, C. J., G. P. Keefe, I. R. Dohoo, K. E. Leslie, R. T. Dingwell, L. DesCôteaux, and H. W. Barkema. 2006. Efficacy of using an internal teat sealer to prevent new intramammary infections in nonlactating dairy cattle. J. Am. Vet. Med. Assoc. 228:1565-1573. https://doi.org/10.2460/javma.228.10.1565.

Sargeant, J. M., A. M. O'Connor, I. A. Gardner, J. S. Dickson, M. E. Torrence, I. R. Dohoo, S. L. Lefebvre, P. S. Morley, A. Ramirez, and K. Snedeker. 2010. The REFLECT statement: reporting guidelines for randomized controlled trials in livestock and food safety: explanation and elaboration. J. Food Prot. 73:579-603. https://doi.org/10.4315/0362-028X-73.3.579.

Scherpenzeel, C. G. M., I. E. M. den Uijl, G. van Schaik, R. G. M. Olde Riekerink, J. M. Keurentjes, and T. J. G. M. Lam. 2014 Evaluation of the use of dry cow antibiotics in low somatic cell count cows. J. Dairy Sci. 97:3606-3614. https://doi.org/10.3168/ jds.2013-7655.

Schukken, Y. H., J. A. H. Smit, F. J. Grommers, D. Vandegeer, and A. Brand. 1989. Effect of freezing on bacteriologic culturing of mastitis milk samples. J. Dairy Sci. 72:1900-1906. https://doi.org/ 10.3168/jds.S0022-0302(89)79309-7.

Shook, G. E. 1993. Genetic improvement of mastitis through selection on somatic cell count. Vet. Clin. North Am. Food Anim. Pract. 9:563-577. https://doi.org/10.1016/S0749-0720(15)30622-8.

Torres, A. H., P. J. Rajala-Schultz, F. J. DeGraves, and K. H. Hoblet. 2008. Using dairy herd improvement records and clinical mastitis history to identify subclinical mastitis infections at dry-off. J. Dairy Res. 75:240-247. https://doi.org/10.1017/S0022029908003257.

Vasquez, A. K., D. V. Nydam, C. Foditsch, M. Wieland, R. Lynch, S. Eicker, and P. D. Virkler. 2018. Use of a culture-independent on-farm algorithm to guide the use of selective dry-cow antibiotic therapy. J. Dairy Sci. 101:5345-5361. https://doi.org/10.3168/jds .2017-13807.

Woolford, M. W., J. H. Williamson, A. M. Day, and P. J. Copeman. 1998. The prophylactic effect of a teat sealer on bovine mastitis during the dry period and the following lactation. N. Z. Vet. J. 46:12-19. https://doi.org/10.1080/00480169.1998.36044.

\section{ORCIDS}

Fidèle Kabera @ https://orcid.org/0000-0003-4890-4036 Simon Dufour ( ) https://orcid.org/0000-0001-6418-0424 Greg Keefe @ https://orcid.org/0000-0003-2356-7344 Marguerite Cameron (ํ) https://orcid.org/0000-0003-4883-8374 Jean-Philippe Roy ๑ https://orcid.org/0000-0002-0444-2303 